ARTIGOS

\title{
SOBRE ALUNOS INDÍGENAS NA UNIVERSIDADE: DISPOSITIVOS E PRODUÇÃO DE SUBJETIVIDADES*
}

\author{
Flávia Marinho LisbôA ${ }^{1}$ \\ IvÂNIA dos SANTOS Neves ${ }^{2}$ (D)
}

\begin{abstract}
RESUMO: Neste artigo, analisamos enunciados de estudantes indígenas da etnia Gaviáo, da recém-criada Universidade Federal do Sul e Sudeste do Pará (Unifesspa), registrados em rodas de conversas promovidas em suas respectivas aldeias, onde relataram suas experiências e expectativas com o Ensino Superior. Recortamos partes das falas de 10 desses estudantes e utilizamos também duas publicaçóes da Unifesspa com foco nos estudantes indígenas. Como referência teórico-analítica, tomamos o conceito de dispositivo de Michel Foucault e a perspectiva arquegenealógica para entender as transformaçóes históricas que culminam na atualidade, apontando como a presença indígena tem desestabilizado a homogeneidade acadêmica.
\end{abstract}

Palavras-chave: Dispositivo. Universidades. Análise do discurso. Indígenas. Amazônia.

\section{ABOUT INDIGENOUS STUDENTS AT THE UNIVERSITY: DEVICES AND PRODUCTION OF SUBJECTIVITIES}

ABSTRACT: This article analyzed statements by indigenous students of the Gaviáo ethnic group, from the newly created Universidade Federal do Sul e Sudeste do Pará (Unifesspa), recorded in talks promoted in their respective villages, where they reported their experiences and expectations in College Education. We edited parts of 10 of these students' speeches and also used two Unifesspa publications focused on indigenous students. As theoretical-analytical reference, take the device's concept of Michel Foucault and the arqueo-genealogical perspective

\footnotetext{
*Este trabalho resulta da pesquisa de doutorado da primeira autora pelo Programa de Pós-Graduação em Letras, da Universidade Federal do Pará (UFPA) intitulada Lingua como linha de força do dispositivo colonial: os Gaviāo entre a aldeia e a universidade. Registra-se que houve recebimento de bolsa da Coordenaçáo de Aperfeiçoamento de Pessoal de Nível Superior (CAPES) por alguns meses para o desenvolvimento da tese. ${ }^{1}$ Universidade Federal Rural da Amazônia - Belém (PA), Brasil. E-mail: flaviamlisboa@gmail.com ${ }^{2}$ Universidade Federal do Pará - Belém (PA), Brasil. E-mail: ivanian@uol.com.br DOI: 10.1590/ES0101-73302019219239
} 
to understand the historical transformations that culminate in the present, pointing out how the indigenous presence have destabilized academic homogeneity.

Keywords: Device. Universities. Speech analysis. Indigenous people. Amazon.

\title{
SOBRE ESTUDIANTES INDÍGENAS EN LA UNIVERSIDAD: DISPOSITIVOS Y PRODUCCIÓN DE SUBJETIVOS
}

\begin{abstract}
RESUMEN: En este artículo analizamos declaraciones de estudiantes indígenas del grupo étnico Gavião, de la recién creada Universidad Federal del Sur y Sudeste de Pará (Unifesspa), registrados en rondas de conversación promovidas en sus respectivas aldeas, donde informaron sus experiencias y expectativas en la Educación Superior. Recortamos porciones de 10 de los discursos de estos estudiantes y también utilizamos dos publicaciones de Unifesspa centradas en estudiantes indígenas. Como referencia teórica y analítica, tomamos el concepto de dispositivo de Michel Foucault y la perspectiva arqueológica para comprender las transformaciones históricas que culminan en el presente, señalando cómo la presencia indígena ha desestabilizado la homogeneidad académica.
\end{abstract}

Palabras clave: Dispositivo. Universidades. Análisis del discurso. Indigena. Amazon.

\section{Introdução}

$\mathrm{E}$

m 1808, a vinda da família real para o Brasil alteraria profundamente as condiçóes institucionais da primeira colônia portuguesa da América do Sul, que a partir daquele acontecimento passaria a compor o Reino Unido de Portugal, Brasil e Algarves. Com essa nova condição, de sede do império, D. João VI precisou promover uma série de reformas na dinâmica social local e, entre outras medidas, criou as duas primeiras faculdades de medicina no país.

Quando D. João VI chegou ao Brasil, uma de suas primeiras providências foi lançar bases para a edificação do Ensino Superior no país. Antes disso, a fundação de faculdades na América Portuguesa era proibida por Alvará Régio. Se em outras áreas coloniais da América as universidades surgiram ainda no século XVI, aqui, durante muito tempo, os filhos da elite colonial precisavam ir para a Europa para completarem seus estudos (ALVES; PASCUETO, 2008, p. 1).

A criação dessas faculdades estava destinada aos portugueses que acompanharam a família real e não havia nenhum desejo de popularizar a educação, ou ain- 
da de comprometer o ensino superior com a diversidade de conhecimentos existentes na, então, colônia. Assim, nesses pouco mais de dois séculos, seguindo na mesma direção da colonização, tanto indígenas, como afro-brasileiros e de forma geral a população mais pobre do país, estiveram à margem de ensino superior no Brasil.

Apenas em 2003 entrou em vigor a Lei $n^{\circ} 10.639$, que alterou a Lei $\mathrm{n}^{\circ}$ 9.394/1996 e estabeleceu nas diretrizes e bases da educação nacional a obrigatoriedade da temática História e Cultura Afro-Brasileira, no currículo oficial da rede de ensino. A inclusão dos indígenas, no entanto, aconteceu apenas cinco anos depois, em 2008, com a Lei $n^{\circ} 11.645$. No avanço dessas conquistas, em 29 de agosto de 2012 foi criada a Lei Federal no 12.711, que estabeleceu cotas para o ingresso de negros, negras e indígenas nas instituiçóes federais de ensino, como as universidades.

Propomo-nos, neste artigo, a refletir sobre a entrada de estudantes indígenas nas universidades, a partir de um caso específico que é a recém-criada Unifesspa ${ }^{1}$. Tomaremos como objeto de análise enunciados de alunas e alunos indígenas ${ }^{2}$ (desistentes ou que ainda cursam a graduação), além de duas publicações da referida universidade, para mostrar como é imperativo que a instituição dialogue com esses sujeitos. A presença indígena sempre foi muito forte na região, mas historicamente eles não estiveram presentes no contexto acadêmico. Na atualidade, como resultado da luta desses povos, a implementação de políticas afirmativas específicas para os povos originários, como a política de cotas e o Processo Seletivo Especial (PSE) ${ }^{3}$ com reserva de vagas, eles passaram a se inscrever nesse espaço monocultural das universidades.

Nossa trajetória de pesquisa imperativamente nos levou para além dos muros da universidade, pois logo surgiu a necessidade de conhecer, de forma mais vertical, a realidade desses alunos e alunas indígenas. Não podíamos visitar todas as terras pelas grandes distâncias entre elas. A aproximaçáo com os Gaviôes ${ }^{4}$, etnia que reúne o maior número de alunos indígenas da Unifesspa, nos fez chegar à Terra Indígena Mãe Maria, onde vivem atualmente. Ela está localizada no município de Bom Jesus do Tocantins, distante apenas 30 quilômetros de Marabá, onde se localizam os principais campi da Unifesspa, no sudeste do estado do Pará.

Durante a realização do trabalho de campo, 33 alunos Gaviáo participaram de rodas de conversas, mas aqui compusemos nosso corpus com o recorte das falas de 10 desses estudantes, mais especificamente. Sobre o perfil desses alunos, chamou a nossa atenção o fato de continuarem morando quase todos em suas aldeias, uma singularidade não observada, por exemplo, na UFPA, em Belém, que recebe alunos de outros estados e mesmo de outras regióes brasileiras. A localização dos principais campi da Unifesspa próximos às aldeias Gaviôes contribui bastante para esta situação. Também analisamos um cartaz de divulgação e uma nota de esclarecimento publicada no Facebook, ambos produzidos pela Unifesspa com relação à presença indígena. 
Como principal referência teórico-metodológica, elegemos duas formulaçóes de Michel Foucault (1988; 2008; 2010; 2014): a perspectiva arquegenealógica, para entender as transformaçóes históricas que culminaram com a chegada dos alunos indígenas às universidades e o conceito de dispositivo. Este conceito permite-nos tratar dos acontecimentos históricos e discursivos sobre a presença indígena na atual Unifesspa, exigindo que os enunciados produzidos por esses alunos hoje sejam relacionados a um arquivo que remonte historicamente a (não) relação dos indígenas com a universidade na região. Com a perspectiva arquegenealógica, pretendemos reconhecer as articulaçôes que os enunciados dos estudantes indígenas estabelecem com os poderes na produção de verdades historicamente estabelecidas nas universidades brasileiras.

Tomamos como referência para entender melhor o conceito foucaultiano de dispositivo as contribuiçóes de Deleuze (1996), que analisa as curvas de visibilidade e de enunciabilidade, de força e de subjetivação, como elementos constitutivos dos dispositivos de poder. Também consideramos as formulações de Gregolin (2015), que elucida esse conceito dentro da obra de Foucault e propóe a existência de um dispositivo escolar no Brasil. Além disso, estudamos Neves (2009), para quem o dispositivo colonial continua agindo na contemporaneidade com suas poderosas estratégias de silenciamento dos saberes indígenas.

Para o desenvolvimento deste trabalho, apresentamos primeiro as emergências históricas que envolvem os Gaviōes e a relação com a universidade na região em que vivem. Em seguida, apresentamos o conceito de dispositivo com suas linhas/curvas e chegamos então às consideraçôes do que a análise com o dispositivo nos permite ver de novo, isto é, aquilo que estamos nos tornando nas universidades.

\section{Algumas emergências históricas dos Gaviões}

Os Gaviōes vivem hoje na Terra Indígena Mãe Maria, no sudeste paraense, a partir da reunião de três grupos do povo Timbira: os Parkatejê, os Kyikatejê e os Akrátikatejê, iniciada sistematicamente pela FUNAI em 1966. Antes de serem reunidos na Terra Indígena, os três grupos passaram por severos processos de aniquilamento e depopulação por causa da construção da hidrelétrica de Tucuruí, da abertura das grandes rodovias no estado do Pará, da extração de castanha, entre outros fatores ligados à expansão do capital na Amazônia, como a agropecuária. É nessa conjuntura que os Gavióes têm contato com os não indígenas, por meio das frentes de expansão econômica na região, que os transforma em invasores de seu próprio território originário, de forma que "os Gaviōes, comenta Nimuendaju (1946 20), eram então reputados como de grande agressividade... [e a] população pedia, constantemente, o extermínio da tribo" (ARNAUD, 1964, p. 2-3). 
Como os sobreviventes dos três grupos perceberam que estavam próximos da extinção, essa complexa reunião na Terra Indígena representou a busca de unidade para os grupos, uma estratégia de fortalecimento (FERRAZ, 1998). Atualmente, depois do aumento populacional, eles começaram a demarcar suas singularidades e, hoje, habitam diferentes aldeias dentro da Terra Indígena. Os nossos interlocutores são alunos da Unifesspa pertencentes aos três grupos citados e em nossa pesquisa de campo convivemos com suas diferenças.

A Unifesspa está inserida nessa fronteira para os povos indígenas no Brasil, na Amazônia, na mesorregião sudeste paraense, onde existem atualmente 50 aldeamentos de nove etnias diferentes, totalizando cerca de 4.400 indígenas. Com suas histórias particulares, eles vivem em intensa relação de conflito com a sociedade nacional, resistindo desde a colonização contra os processos de expansão do capital na regiâo. Por estarem historicamente situados nessa mesorregião, as condiçôes de possibilidades históricas estabelecidas pelas conquistas sociais dos primeiros anos do século XXI permitiram a problematização da invisibilidade das demandas desses sujeitos e dessas sujeitas em relação ao acesso a essa universidade. Como resultado de reivindicaçóes feitas por parte dos indígenas do Pará e Tocantins, esse novo reposicionamento das universidades brasileiras começou a se efetivar em políticas afirmativas em 2010, quando o campus ainda fazia parte da UFPA.

Como açōes estratégias para a permanência dos alunos indígenas, eles contam com quatro importantes incentivos:

- o PSE que dá acesso diferenciado às duas vagas reservas por curso na instituição;

- $\quad$ cotas via processo seletivo regular em atenção à Lei Federal no 12.711;

- Bolsa Permanência no valor de R \$900, subsidiada via Ministério da Educação (MEC);

- disponibilização de monitoria para ajudar os alunos com dificuldades nas disciplinas.

Duas dessas açóes, a Lei de Cotas e a Bolsa Permanência são parte de políticas de inclusão instituídas pelo governo federal, enquanto o PSE, atrelado à reserva de duas vagas em cada curso, e a monitoria são iniciativas de ação afirmativa da própria Unifesspa.

\section{Dispositivos de poder: percursos teórico-metodológicos}

Michel Foucault nunca discutiu propriamente o conceito dispositivo em nenhum de seus livros. Em sua obra, ele definiu dois dispositivos mais especificamente, 
o da sexualidade e o da segurança, mas náo explicitou o conceito. Em uma entrevista concedida em 1977, ele exemplificou o dispositivo, dizendo que é um

Conjunto decididamente heterogêneo que engloba discursos, instituiçóes, organizaçóes arquitetônicas, decisóes regulamentares, leis, medidas administrativas, enunciados científicos, proposiçôes filosóficas, morais, filantrópicas. Em suma, o dito e o não dito são os elementos do dispositivo. O dispositivo é a rede que se pode estabelecer entre estes elementos (FOUCAULT, 1999, p. 244).

O conceito é tratado pelo autor como uma ideia operacional para analisar o poder nas relaçóes sociais, no funcionamento das instituições, leis, isto é, nas mais variadas formas de se exercer, administrar o controle social, já que sempre o conceito de dispositivo está inscrito num jogo de poder. Ainda nessa entrevista, ele afirma:

O dispositivo, portanto, está sempre inscrito em um jogo de poder, estando sempre, no entanto, ligado a uma ou a configuraçóes de saber que dele nascem, mas que igualmente o condicionam. É isto, o dispositivo: estratégias de relaçóes de força sustentando tipos de saber e sendo sustentadas por eles (FOUCAULT, 1999, p. 146).

No livro História da sexualidade 1, podemos ver o autor operacionalizando o conceito, mas sem defini-lo ou explicá-lo propriamente. Nessa obra, o autor refere-se regularmente ao conceito na tentativa de mostrar como a sexualidade foi historicamente construída como um dispositivo do poder:

O dispositivo de sexualidade se liga à economia através de articulaçôes numerosas e sutis [...] o dispositivo de sexualidade tem, como razáo de ser, não o reproduzir, mas o proliferar, inovar, inventar, penetrar nos corpos de maneira cada vez mais detalhada e controlar as populaçóes de modo cada vez mais global (FOUCAULT, 1988, p. 118).

Em Segurança, Território, População, Michel Foucault (2008), para definir seu conceito de governamentalidade, valeu-se da descrição histórica do dispositivo de segurança. Ele procurou mostrar como os processos de controle da população vão superar as estratégias de disciplina e compor um dispositivo de poder mais invisível e com alcance maior.

Por esta palavra, "governamentalidade", entendo o conjunto constituído pelas instituiçóes, os procedimentos, análises e reflexôes, os cálculos e as táticas que permitem exercer essa forma bem específica, embora muito complexa, de poder que tem por alvo principal a populaçáo, por principal forma de saber a economia política e por instrumento técnico essencial os dispositivos de segurança (FOUCAULT, 2008, p. 143). 
Para Gregolin (2015, p. 11), "o objetivo de diagnosticar e compreender a racionalidade de práticas sociais do saber e do poder" está na base da arquegenealogia foucaultiana e o conceito de dispositivo foi elaborado para dar conta de analisar a heterogeneidade das práticas (não) discursivas, como ele fez ao propor a história da sexualidade. A autora analisou a criação do dispositivo escolar na República brasileira e procurou mostrar como a escola pública começou a afetar um número maior de pessoas. Nesse processo, as matrizes culturais indígenas sistematicamente ficaram do lado de fora, pois representavam o atrasado, o selvagem, o não culto.

Para Neves (2009), existe um dispositivo de saber e poder que emergiu com o sistema colonial europeu e se atualizou nas práticas contemporâneas. Esse dispositivo colonial sempre se reposicionou diante das movimentaçôes históricas e conseguiu se estabelecer mesmo depois dos processos de independência das ex-colônias:

[As] instituiçôes ocidentais criaram uma série de estratégias de dominação, dispositivos que agenciavam a exploração de riquezas florestais e minerais, mas que se estruturavam na construção de cidades, na imposição de línguas oficiais, e que também estabeleceram os processos de sujeição impostos às sociedades indígenas. Para Foucault, dispositivo é um determinado agrupamento de práticas, que constituem um sujeito em uma trama de saberes e em um jogo de forças que lhes são imanentes (NEVES, 2009, p. 32).

Entendemos o dispositivo como estratégia para sustentar determinadas relações de poder que se estabelecem pela implantação de verdades, mas, por meio de processos de subjetivação, essas relaçóes podem ser fissuradas, fraturadas ou ainda mantidas por novas reelaboraçóes do mesmo jogo. Os dispositivos não são sistemas isolados de poder, muito pelo contrário, muitas vezes eles se complementam. Nesse processo tardio de inclusão dos alunos indígenas nas universidades brasileiras, o funcionamento do dispositivo escolar proposto Gregolin (2015) e do dispositivo colonial defendido por Neves (2009) foram bastante decisivos.

$\mathrm{Na}$ diversidade de perspectivas do grande quadro teórico proposto por Michel Foucault, o conceito de dispositivo faz parte das referências relacionadas à sua fase genealógica.

A genealogia do poder propóe diagnosticar e compreender a racionalidade das práticas sociais que nos subjetivaram pelos seus efeitos e nos objetivaram pelas suas tecnologias, e a genealogia da ética busca problematizar as práticas de si e os processos de subjetivação que ligam o sujeito à verdade (GREGOLIN, 2015, p. 9).

Assim, o trabalho com o conceito de dispositivo nos dá condiçóes metodológicas para mostrar como o poder e o saber agem para manter essa ordem 
que opera com status de verdade nas universidades brasileiras. Por outro lado, ele também permite visibilizar como esse processo está permanentemente sendo infiltrado pelas produçóes de novas subjetividades. Os estudantes indígenas que ouvimos em nossa pesquisa, pelas suas experiências com a Unifesspa, assim como algumas atitudes da reitoria e dos professores da universidade, podem reforçar ou estabelecer pequenas fissuras nessa verdade posta.

\section{$\underline{\text { As linhas do dispositivo }}$}

Com base na leitura de Deleuze (1996), podemos compreender o dispositivo foucaultiano estruturado em quatro linhas, ou curvas: visibilidade, enunciação, força e subjetivação. Para o autor, essas linhas não delimitam ou envolvem sistemas homogêneos, mas compóem processos em permanente desequilíbrio, como resultado da produção de subjetividade, impelindo respostas dentro do dispositivo que, por sua vez, tenta ao máximo manter determinada ordem.

Por outro lado, as produçôes de novas subjetividades podem tencioná-lo a tal ponto que chegam então a provocar sedimentaçóes, ou reconfiguraçóes, ou mudanças ou até mesmo transformaçóes radicais no dispositivo chegando a possibilitar a emergência de outro dispositivo. Para analisar as falas dos alunos e os acontecimentos que os envolvem, tomamos o funcionamento das linhas nos termos de Deleuze (1996):

- Visibilidade: cada dispositivo tem uma historicidade, um regime que distribui luz para selecionar o visível e o invisível, conferindo existência aos objetos, que só nascem ou desaparecem pela linha de visibilidade. Nos enunciados expostos no Quadro 1, notamos como essa linha atua, deixando invisíveis os indígenas, mesmo depois de ter sido adotada uma política de entrada na universidade para esses sujeitos. Trata-se de dois exemplos de como a universidade invisibiliza os alunos indígenas desde a entrada até a saída. No primeiro caso, a aprovação desse aluno no PSE não produziu nenhuma repercussão no curso de Educação no Campo e não houve nenhuma preparação para recebê-lo. Segundo seus relatos, essa invisibilidade o acompa-

\section{Quadro 1}

Enunciados para a linha da visibilidade.

ALUNO 1, 25 anos, Educação do Campo, 2017: "Quando eu fui fazer a inscrição, nem as pessoas do curso sabiam que o curso tinha cota, aí eu mostrei que eu tinha passado"

ALUNA 2, 21 anos, Direito 2016: "Eu até falei com a universidade, que vocês fizeram intercâmbio para juntar os indígenas e poder ouvir eles e eles disseram: 'Que vergonha! $O$ primeiro indígena se formou pela Unifesspa e ninguém viu!'. A universidade não viu, a universidade não deu valor. Entấo, é isso! A universidade também não acompanha a gente." 
nhou durante todo o curso, pois passou todo o tempo de graduação sem um tratamento diferenciado. No segundo caso, temos a reclamação de que o aluno sai da universidade assim como ele entrou: invisível. Esse enunciado denuncia que a universidade não joga luz, nos termos de Deleuze (1996), sobre esses alunos, não evidencia sua presença nas práticas de acompanhamento desse estudante;

- Enunciado: as linhas de enunciação dão conta de materializar as linhas de visibilidade, selecionando e distribuindo elementos de forma a atender os regimes que norteiam o dispositivo. No entanto, só podemos definir esses regimes pelo enunciado, observando sua historicidade com as assimilações e mudanças que adota ao longo do tempo. Por meio dos exemplos exibidos no Quadro 2, apresentam-se situaçōes de como os enunciados indígenas existem, ou não, na universidade. Essas falas evidenciam como as práticas docentes e dos colegas de graduação nas situaçōes relatadas são a do silenciamento dos alunos indígenas. São práticas que reforçam a condição de indesejado que esses alunos mantêm, fazendo com que seu silenciamento seja cada vez mais naturalizado por meio dessas açóes de repressão nas poucas vezes em que têm coragem de falar. Elas reforçam o dispositivo colonial e sua hierarquização racial. Sabemos que o enunciável é sempre negociado pelas condiçôes de possibilidade históricas de forma que as instituiçôes de poder, nesse caso a universidade, não se reposicionam sem que suas verdades sejam provocadas pelos sujeitos subalternizados. Para Foucault (2010), os silenciamentos são produzidos, sobretudo, pela institucionalização de verdades, que definem o que é o normal em uma sociedade. Nas atuais conjunturas, embora a universidade, como estamos mostrando, ofereça muita resistência aos alunos indígenas, ela não pode mais se esquivar

\section{Quadro 2}

Enunciados para a linha do enunciado.

ALUNA 3, 25 anos, Direito 2017: "Na universidade, se a gente pergunta, todo mundo para e fica olhando pra gente [...] quando a gente pergunta, eles ficam olhando com uma cara diferente porque não queriam ser interrompidos por aquilo. Tem muitos que estudaram só em escola particular e quando a gente pergunta a professora pergunta: 'vocês não estudavam, não?', 'Ô professora, a gente estudou sim, mas em escola pública.."

ALUNO 4, 30 anos, Geografia 2011: "A maior dificuldade é a dinâmica da universidade: ela tem seu tempo e não espera pela gente. E se a gente pergunta, o professor e a turma tratam como se fôssemos o atrasado.".

ALUNO 5, 27 anos, Geografia: "nós precisamos criar uma representaçáo aqui dentro, nossa, indígena [...] Eu quero que a representação indígena aqui seja forte aqui dentro. Nós indígenas tem que se impor, porque nós aqui também faz parte [...]. Sempre que tem reunião nós tem que participar, o representante indígena em reuniâo aí com reitor com coordenação tem que participar porque a gente faz parte da universidade." 
desse diálogo, nem mesmo acatar como verdadeiros enunciados contrários à cooperação. Por outro lado, a própria instituição oferta as vagas aos alunos e não pode ignorar os problemas advindos desse acesso. Essa proposição fica mais bem compreendida adiante, quando tratamos de dois enunciados da universidade na linha de subjetivação;

- $\quad$ Força: essa linha ocupa toda a existência do dispositivo, uma vez que é a "dimensão do poder" interior ao dispositivo, impulsionando todas as outras linhas como a força que direciona a visibilidade, permite o dizível e orienta a forma de lidar com as produçóes de subjetividade. Encaixam-se também, aqui, todos os exemplos já dados nas linhas de visibilidade e enunciado. Nesse sentido, apresentam-se, no Quadro 3, exemplos da força

\section{Quadro 3}

Enunciados para a linha de força.

ALUNO 5, 27 anos, Concluinte de Geografia: "Quando a gente chega aqui, a gente encontra tipo uma barreira... E isso... muitos indígenas que entraram junto com a gente desistiram, porque tiveram dificuldade, não tinha apoio, pra onde correr."

ALUNA 6, 22 anos, Direito 2016: "Quando eu entrei na faculdade, eu já me deparei com toda uma situação complicada, né? Principalmente na questáo de informaçâo, de acesso ...A gente tem que tá ali conectado à internet pra saber a data de fazer matrícula, a data de levar documentação, que documentação levar, onde eu vou quando eu chegar, com quem eu vou falar... Até quando a gente entra na faculdade, começa a conhecer coisas que a gente nunca viu, na vida. Totalmente assim: dificil, porque eu nunca tive! Lá fora, as pessoas já estão acostumadas com essas dinâmicas, já tem facilidade e quando o professor passa o conteúdo, todo mundo já está ali envolvido, a gente fica se sentindo assim o excluido: 'Meu deus do céu, eu sou muito burra!"”

ALUNA 7, 35 anos, Pedagogia 2012: "E a informática também está lá pra eles. Por nós não termos esse conhecimento, dificulta. Até hoje eu tenho dificuldade com informática. E naquela época eu pensava: eu não tenho computador, eu não sei muito manusear computador, como é que eu vou fazer."

ALUNA 8, 22 anos, Pedagogia 2015: "Aí, quando eu entrei lá, eu pensei que fosse que nem a gente estudava aqui, mas ai eu vi que era muito diferente do que a gente estudava aqui. Aqui, eu nunca apresentei um seminário, eu nunca apresentei trabalho assim na frente e lá não."

ALUNO 9, 40 anos, Letras 2015: "Falando um pouco das dificuldades dentro da universidade, é que a universidade não está preparada para receber os indígenas. Esse é o primeiro ponto. O segundo é que mesmo os indígenas sendo preparado, ele não consegue acompanhar porque está muito avançado."

ALUNO 4, 30 anos, Geografia 2011: "Eu vejo que a dificuldade dos alunos na universidade náo tanto o acesso, mas sim poder acompanhar a universidade... A universidade tem uma hierarquia de que às vezes a gente coloca dificuldade, mas vejo como um desafio... Muitos da minha época, muitos desistiram e náo conseguiram por causa desse acesso [...]. A maior dificuldade é a dinâmica da universidade: ela tem seu tempo e não espera pela gente. E se a gente pergunta, o professor e a turma tratam como se fôssemos o atrasado."

ALUNA 2, 21 anos, Direito 2016: "Mas é muito forte, o indígena ainda é visto como tabu."

ALUNO 10, 25 anos, Economia 2015: "Para muitos... acham que eu não mereço isso aqui.

Mas todo dia na universidade é dia de reconquistar algum espaço, ne? De mostrar que a gente tem essa capacidade e conseguir a confiança de alguns companheiros lá dentro, professores também." 
se materializando em situaçóes em que a universidade impóe sua estrutura bastante imbricada ao dispositivo colonial e invisibiliza o diverso. As instituiçóes do Estado recorrentemente se valem de uma política burocrática e formal, herdada da colonizaçáo europeia, e se tornam inalcançáveis às pessoas que não foram constituídas com tais práticas. Esses enunciados foram selecionados para mostrar como a força do dispositivo escolar, nesse caso a universidade, se impóe de diversas formas sobre os sujeitos. Não dominar práticas de linguagem é decisivo para a desistência dos alunos, como vemos nos próprios relatos a recorrência da constataçáo: "por isso... muitos desistiram". Essa força manifesta-se na falta de informação (de forma acessível a esse público específico) aos ingressantes indígenas sobre as especificidades dos cursos da instituição ("eu entrei sem saber o que era") ${ }^{5}$. Manifesta-se também na falta de preparação desses calouros para lidar com o ambiente acadêmico, ambientação esta que requer conhecimentos de informática, do funcionamento burocrático e da linguagem acadêmico-científica que se manifesta nos gêneros acadêmicos nunca antes vivenciados por eles, entre os quais está o seminário. Diante de tantas dificuldades, as conquistas dos indígenas no ensino superior ainda são ganhos limitados, que não conferem continuidade à educação intercultural, bilíngue e diferenciada em execuçấo (ainda que com sérias dificuldades) em algumas aldeias na educação básica. Entendemos que as mudanças necessárias para a permanência desses estudantes na universidade náo vão acontecer com um gesto de sensibilidade por parte do poder institucionalizado na universidade, mas sim pelo tensionamento provocado pelos indígenas que agora, dentro das universidades e reféns dessas condiçôes adversas, vão poder reivindicar com mais propriedade tais melhorias. Então, se antes a força utilizada pela universidade era negada aos indígenas pela forma de seleção, após a adoção de um processo seletivo especial para esse público a linha de força se mantém hoje na necessidade de domínio de certos conhecimentos, que a instituição toma como "prévios". Diante dessas situaçōes, os próprios alunos concluíram que a universidade não está preparada para receber os indígenas. Essa falta de diálogo com outras culturas e a inadaptação da universidade, no entanto, aos olhos da sociedade, são equivocadamente interpretadas como incapacidade do indígena, aquele que não consegue acompanhar, o atrasado, e eles mesmos percebem a construção desse discurso sobre si. Nesse sentido, o seguinte trecho de Foucault ajuda-nos no refinamento da reflexão a respeito da atuação das linhas de força no âmbito educacional:

Sabe-se que a educação, embora seja, de direito, o instrumento graças ao qual todo o indivíduo, numa sociedade como a nossa, pode ter acesso a qualquer tipo de discurso, segue, em sua distribuição, no que permite e no que impede, as linhas que estão marcadas pela distância, pelas oposiçóes e pelas lutas sociais. 
Todo sistema de educação é uma maneira política de manter ou de modificar a apropriaçáo dos discursos, com os saberes e os poderes que eles trazem consigo (FOUCAULT, 2011, p. 44).

A universidade mobilizou-se para tornar-se acessível aos alunos quando instituiu o PSE, mas precisa estabelecer novas açóes, para que esse processo possa se efetivar de fato, sem um número de evasão expressivo e não falir logo no primeiro acesso desses sujeitos à instituição. Ela precisa flexibilizar a forma de apropriação dos conhecimentos acadêmicos e se reposicionar como um espaço de poder que considere as diferentes práticas culturais. A monitoria não resolve a resistência de professores e alunos não indígenas, nem consegue pluralizar os currículos de forma que também incorporem os saberes indígenas;

- Subjetivação: a linha de subjetivação é tomada por Deleuze (1996) como o espaço dentro do dispositivo em que se manifestam as reaçóes impulsionadas pela visibilidade, enunciado e força. É onde se pode ver os efeitos dos tensionamentos dos sujeitos sobre as verdades postas pelo dispositivo, fazendo com que este (dependendo da forma como essas produçóes de subjetividade se manifestem) se sedimente ou assimile pequenas alteraçóes, ou mesmo frature-se. Da mesma forma, por outro lado, o nível de rigidez em que o dispositivo se encontra, em determinado momento social e histórico, também afeta a produção de subjetividade em sua intensidade e capacidade de potencializar o novo.

A fornecer novos saberes e a inspirar novos poderes. Podemos perguntar se as linhas de subjectivação não são o extremo limite de um dispositivo, e se náo esboçam elas a passagem de um dispositivo a um outro: neste sentido, elas predispóem as "linhas de fractura" [...] produçóes de subjectividade que saem dos poderes e dos saberes de um dispositivo para se reinvestir noutro, sob outras formas que hão-de nascer (DELEUZE, 1996, p. 84).

$\mathrm{Na}$ linha de subjetivação, é possível acontecer a fuga, o escape aos regimes de poder estabelecidos por meio de saberes que constroem verdades instituídas. Nessa última linha, é o espaço em que se marca

a capacidade de [o dispositivo] se transformar, ou se fender, se enfraquecer da força nas linhas mais duras, mais rígidas, ou sólidas [...] As linhas de subjectividade parecem ser particularmente capazes de traçar caminhos de criação, que não cessam de fracassar, mas que também, na mesma medida, são retomados, modificados, até a ruptura do antigo dispositivo [...]. As linhas de subjetividade seriam responsáveis, então, pela: estratificação ou de sedimentação X linhas de actualização ou de criatividade (DELEUZE, 1996, p. 84). 
Além das práticas cotidianas narradas pelos alunos indígenas, para adensar um pouco mais nossas análises sobre o posicionamento da instituição diante da presença desses sujeitos e os efeitos das produçốes de subjetividades frente aos mecanismos de força do dispositivo, selecionamos um cartaz de divulgação e uma nota de esclarecimento produzidos pela Unifesspa com enfoque nos indígenas. Tanto no cartaz (Figura 1) como na nota de esclarecimento (Figura 2), a Unifesspa apresenta-se como uma universidade diversa.

No primeiro enunciado (Figura 1), a presença, entre outros sujeitos, de indígenas Suruí, Guarani, Gavião, Xicrin e Guajajara, etnias que vivem na regiâo e agora estão entrando na universidade, evidencia que a produção de subjetividades indígenas tem provocado o espaço universitário para que se atente à necessidade de modificação de suas práticas discursivas. No segundo enunciado (Figura 2), a instituição mostra-se aberta para essa demanda da diversidade com a preocupação de retratar-se depois de denúncia e repercussão negativa em uma

\section{Figura 1}

Cartaz produzido para divulgar o evento de recepçáo dos calouros citando a participação dos indígenas: Suruí, Guarani, Gavião, Xicrin e Guajajara.

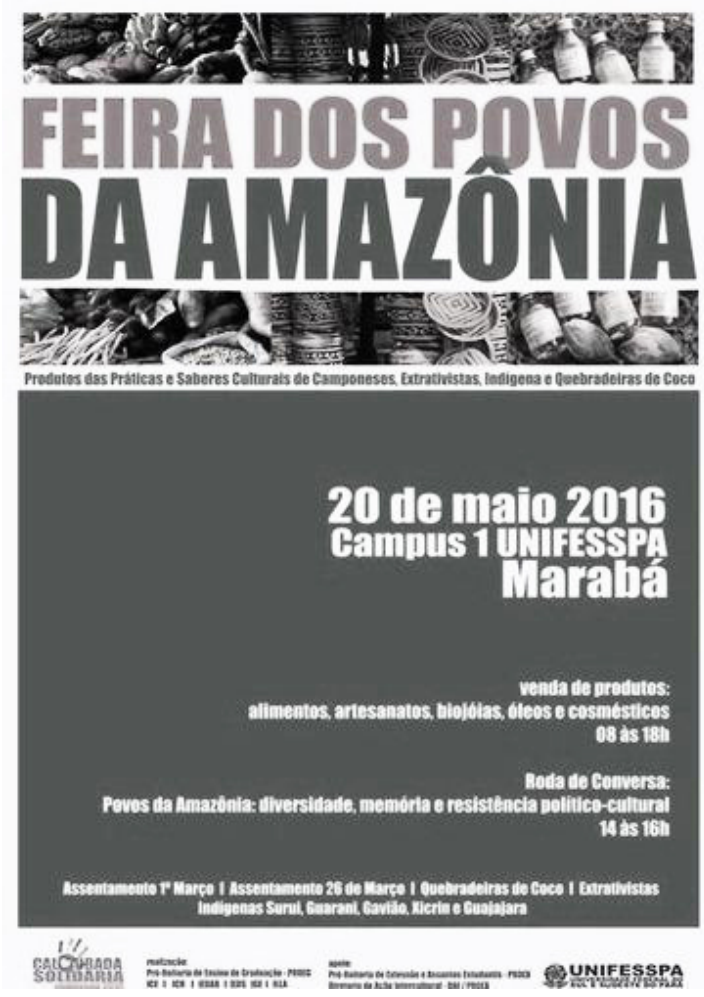

Fonte: Disponivel em: <www.unifesspa.edu.br/> 


\section{Figura 2}

Nota de esclarecimento da Unifesspa sobre pintura de paredes do Campus 1, onde grafites indígenas foram apagados.

\section{Nota de Esclarecimento}

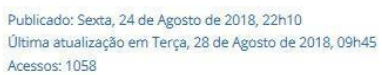

\section{(O) ()}

A Reitoria da Universidade Federal do Sul e Sudeste do Pará (Unifesspa) lamenta profundamente o grave erro cometido durante uma ação de manutenção da pintura de prédios na Unidade I, do Campus de Marabá. A Administração Superior esclarece que em nenhum momento houve a intenção de ocultar ou menosprezar a manifestação artística presente naquele espaço e pede desculpas pela grave falha de comunicação ocorrida entre a equipe de revitalização e a unidade demandante do serviço.

Tão logo a Reitoria tomou conhecimeno do fato, buscou a direção da Faculdade de Ciências Sociais e demais grupos envolvidos na atividade cultural para se desculpar e agilizar um processo de reparação. Por meio da Secretaria de Infraestrutura (Sinfra), a Unifesspa irá fornecer os materiais necessários para que os autores da obra artística possam refazer a pintura, numa atividade a ser pactuada com o Instituto de Ciências Humanas (ICH).

A Unifesspa reafirma o compromisso e esforço na construção de uma universidade plural e diversa.

Fonte: Disponivel em: <https://www.unifesspa.edu.br/noticias/2752>. Acesso em: 16 dez. 2018.

página de Facebook (não oficial e com mais de 10 mil inscritos). A denúncia aconteceu porque uma equipe de revitalização da universidade apagou os grafismos indígenas pintados por alunos indígenas durante atividades acadêmicas das paredes do prédio de Ciências Sociais.

Diante de tudo isso, observamos que essas linhas de subjetivação do dispositivo começaram a se movimentar, no caso da Unifesspa, quando as políticas públicas (por meio das açóes afirmativas herdadas da UFPA com reserva de vagas e o PSE”) foram estabelecidas. É, no entanto, as reaçôes dessas sujeitas e desses sujeitos indígenas diante de novas configurações históricas, com suas várias formas de fuga, por provocar desestabilidades e instaurar o novo, que vão criar condiçóes para que mudanças mais profundas aconteçam.

\section{Arquivo: condições de possibilidades históricas}

Dando seguimento à análise com o dispositivo, Foucault alerta que com ele devemos fazer o diagnóstico do futuro a partir da atualidade e, para isso, precisamos analisar um arquivo, debruçar-nos sobre a história do que fomos no passado e não voltaremos a ser. Para Foucault (1999), só com a análise do arquivo (passado) podemos saber o que somos na atualidade e, com isso, diagnosticar o que estamos nos tornando, projetar o novo que desponta na atualidade. 
O novo é o actual. $\mathrm{O}$ actual não é o que somos, mas aquilo em que nos vamos tornando, aquilo que somos em devir, quer dizer, o Outro, o nosso devir-outro. É necessário distinguir, em todo o dispositivo, o que somos (o que não seremos mais), e aquilo que somos em devir: a parte da história e a parte do actual. A história é o arquivo, é o desenho do que somos e deixamos de ser, enquanto o actual é o esboço daquilo em que vamos nos tornando. Sendo que a história e o arquivo são o que nos separa ainda de nós próprios, e o actual é esse Outro com o qual coincidimos desde já (DELEUZE, 1996, p. 86, grifo do original).

Assim, na análise aqui proposta, relacionamos o passado e o futuro, tomando como elo/ligação a atualidade. Não acreditamos ser possível traçar marcadores fixos para diferenciar passado, presente e futuro e neste artigo, por meio da análise do dispositivo, procuramos evidenciar o que estamos nos tornando na universidade em relação à pluralidade cultural e à presença de alunos indígenas. Com esse objetivo, adotamos como passado toda a história do ensino superior no Brasil até o momento em que a negação de açóes afirmativas foi determinante para a não inserção de indígenas na universidade local. $\mathrm{O}$ presente toma como referência as mudanças ocorridas nos últimos dez anos, que marcam uma virada no percurso educacional indígena na região com implantação de açóes afirmativas, criação de leis e resoluçóes da universidade que viabilizaram a presença dos indígenas na Unifesspa. Esse presente se materializou neste texto nos enunciados proferidos pelos alunos indígenas e pelos posicionamentos da Unifesspa nas Figuras 1 e 2 apresentadas no tópico anterior.

Nesse sentido, reunimos a seguir elementos que nos ajudam a perceber o caminho sócio-histórico que possibilitou a atualidade como ela é, permitindo-nos assim vislumbrar o que estamos nos tornando. Para isso, consideramos as singularidades a seguir como um continuum de conquistas e ganhos para o povo Gaviáo, nos últimos dez anos na universidade implantada na região em que vivem, que compóem as condiçóes de possibilidades históricas para que, hoje, sejam possíveis as existências dos enunciados dos alunos que apresentamos e mesmo os posicionamentos da Unifesspa frente a essa presença indígena.

- $\quad$ Em 2009, a UFPA (em todos os seus campi, inclusive no campus de Marabá, que está próximo das aldeias Gavião) passou a realizar o Processo Seletivo Especial (PSE) para indígenas;

- A Resolução no 3.689/2009 somou, em todos os cursos da UFPA, duas vagas para alunos indígenas às vagas já existentes ${ }^{8}$;

- $\quad$ Foi implantada a Lei Federal no 12.711, de 29 de agosto de 2012, que trata das cotas nas universidades federais e nas instituições federais de ensino técnico de nível médio; 
- Desde sua criação, a Unifesspa mantém todas as políticas da UFPA citadas anteriormente e também mantém a Divisão de Assistência Estudantil (DAIE), um departamento que, além de outras atribuiçōes, pensa açōes de inclusão e permanência dos alunos indígenas na universidade;

- Há três anos foi ofertado aos alunos indígenas o Programa de Nivelamento Indígena';

- Segundo informações da DAIE, desde a implementação das políticas afirmativas, em 2009, apenas quatro alunos indígenas concluíram a graduação até 2016;

- Tanto os alunos como a DAIE apontam a Bolsa Permanência como um fator imprescindível para a permanência desses alunos na universidade;

- Hoje os alunos indígenas contam com um programa de monitoria para dirimir dificuldades nas disciplinas;

- Em 2018, foi criado o Núcleo de Ações Afirmativas, Diversidade e Equidade (Nuade), que se divide em três coordenadorias e uma delas, a Coordenadoria de Questôes Étnico-Raciais, é para onde se destinam as demandas referentes aos alunos indígenas.

\section{Diagnóstico: a atualidade que vislumbra o que estamos nos tornando}

Para esta etapa do diagnóstico, precisamos relacionar o arquivo (composto do passado de negaçáo de políticas de acesso para povos indígenas, ultrapassado nos últimos dez anos como listamos na seção anterior) com o material da atualidade, que são os enunciados analisados do momento presente: as Figuras 1 e 2, como amostra das práticas institucionais dessa universidade, e as falas dos alunos apresentadas nos Quadros 1, 2 e 3.

Esse diagnóstico não pode ser fechado, não desloca uma projeção acabada pela impossibilidade de prever um futuro para os sujeitos, porém é um diagnóstico que fala da atualidade como parte da construção do futuro. Trata-se de uma abordagem que percebe a construção dos sujeitos em um continuum e que, por isso, precisa do passado e do presente para conjecturarmos possíveis desdobramentos futuros.

Sua intenção não é realizar um retorno ao passado, mas antes diagnosticar sua própria atualidade. Esse diagnóstico do presente, entretanto, não se contenta em caracterizar o que somos hoje, mas também tem por função apontar como o que é poderia não mais ser o que é (GREGOLIN, 2015, p. 7-8). 
Como diagnóstico, apontamos nos enunciados que a atual presença de alunos indígenas na universidade tonifica a quebra das tradicionais estruturas acadêmicas, tensionando cada vez mais a necessidade de dar respostas às demandas relacionadas a esses alunos, de forma que o poder institucionalizado, ou seja, a universidade, se vê na condição de necessitar dar visibilidade a esses sujeitos em suas práticas discursivas. Tal situação pode se relacionar à seguinte consideração de Gregolin (2015) a respeito dos tensionamentos do poder pelos sujeitos ao longo da história:

Por ter-se ocupado das relaçóes entre discursos, saberes e poderes, Foucault revolucionou as teorias clássicas do Estado, na medida em que introduziu, nas análises históricas, a ideia de que o poder pode ser considerado como instrumento analítico capaz de explicar a produção dos saberes, sua existência e suas transformaçôes como peças de relaçôes de poder em dispositivos políticos (MACHADO, 1999, p. X). Um importante aspecto dessa inovação teórica foi a historicização do poder, isto é, Foucault mostrou que o poder se modifica sob o impacto das transformaçôes históricas (GREGOLIN, 2015, p. 11).

As subjetividades materializadas nos enunciados dos próprios alunos indígenas em meio às experiências e expectativas sobre a universidade revelam as dificuldades da vivência acadêmica e os conflitos entre as cosmovisóes indígenas e a ocidental. Por outro lado, com os dados que temos hoje, podemos analisar o passado, a história, e diagnosticar que mudanças significativas aconteceram e que estamos nos tornando outra coisa que náo mais o passado, conseguimos perceber movimentos que impulsionam construçôes de uma outra identidade futura para a Unifesspa.

\section{Considerações finais}

Com a análise dos dispositivos de poder que determinaram o ingresso táo tardio dos alunos indígenas na Unifesspa, procuramos fazer um diagnóstico das possibilidades de reposicionamento das verdades instituídas nas universidades brasileiras. Esse diagnóstico não é fechado, ao contrário, é bastante permeável, pois compreende a atualidade como um nó em uma flexível rede discursiva imbricada com acontecimentos do passado, para elaborar conjecturas sobre a construção do futuro. Trata-se de uma abordagem que percebe a construção dos sujeitos em uma linha descontínua e que, por isso, precisa do passado e do presente para chegar a possíveis desdobramentos futuros.

Diante dos dados históricos apresentados ao longo dos tópicos anteriores, do período da colonização até 2010, quando os indígenas passam a fazer parte das políticas afirmativas da UFPA, e posteriormente da Unifesspa, percebemos que esses ganhos foram conquistados via lutas históricas. Os indígenas enfrentaram e ainda 
enfrentam muita resistência tanto dentro como fora da universidade. Eles tensionaram para que fossem contemplados com uma política que garantisse lugar para eles no espaço acadêmico e a luta prossegue por condiçóes de permanência dentro dele.

Com a entrada dos indígenas no ensino superior, está posta a necessidade de problematização de toda a estrutura acadêmica, desde a forma como esse aluno é selecionado, sua recepção na universidade e todo o funcionamento que evidencia o conflito cosmológico entre mundos diferentes: o do branco e os modos de vida indígenas.

Por outro lado, nas novas condiçóes de possibilidades históricas em torno da universidade, percebemos o surgimento do novo, de novos tempos que ainda não existem, mas que pedem passagem para vir a ser e, a menos que sejamos expostos a um estado de exceção, não voltaremos ao passado. A atualidade dos acontecimentos históricos evidencia que um novo se anuncia nos enunciados que circulam, permitindo-nos vislumbrar que o futuro urge no presente, mas que exigirá muitas mobilizaçôes para que possa vir a acontecer.

Se serão tempos melhores, não sabemos, nem é essa a tarefa da análise aqui proposta, mas sim evidenciar que, por meio de dados de um arquivo e do presente, podemos perceber o movimento de mudanças do que estamos nos tornando nas universidades. Embora não possamos ainda afirmar o que pode ser essa nova ordem, ela não é o que está no arquivo, no passado, no que já foi, nem mesmo o que somos hoje no presente.

Diante disso tudo, esperamos, com a reflexáo feita neste artigo, ter alcançado o objetivo de estabelecer as relaçóes entre os dispositivos de poder e o discurso, evidenciando que os regimes, por mais institucionalizados que sejam, são permeáveis e permanentemente tensionados pelas produçôes de subjetividade dos sujeitos frente aos processos de subjetivação.

\section{Notas}

1. A Unifesspa foi criada em 2013 em desmembramento da Universidade Federal do Pará (UFPA), com campi em cinco municípios: Marabá (sede), Rondon do Pará, São Felix do Xingu, Xinguara e Santana do Araguaia.

2. Esses enunciados foram colhidos em encontros nas aldeias dos alunos por meio de rodas de conversas, em trabalho de campo. Para produção dos enunciados, os alunos foram provocados a responder de forma livre aos seguintes questionamentos: Quais as principais dificuldades enfrentadas para se manterem na universidade? Qual é o objetivo com o curso que escolheram estudar na graduação?

3. Os graduandos indígenas da Unifesspa são estudantes aprovados pelo PSE, distribuídos em todos os cursos da universidade, já que há reserva de duas vagas para estudantes indígenas em todas as turmas de graduação. 
4. A constituição dos indígenas conhecidos hoje como Gavião se deu pela junção de três grupos locais (Parkatejê, os Kyikatejê e os Akrãtikatejê) que sofreram "sucessivas remoções compulsórias [e] acabaram por reunir distintos grupos locais em uma única área [...] numa só aldeia, por eles chamada Kupejipôkti, 'os que estão lutando no meio do kupe' (não-índio)” (FERRAZ, 1998, p. 1).

5. Esse exemplo, que parece não ter muita significância neste texto, é uma das ocorrências que mais contribuem para a evasão, pois os alunos ingressam achando que vão fazer algo e depois percebem no decorrer do primeiro semestre que não se identificam com o que veem e vivenciam.

6. Lei que estabelece cotas nas universidades federais e nas instituiçôes federais de ensino técnico de nível médio.

7. Aprova a reserva de duas vagas, por acréscimo, nos cursos de graduação da UFPA a indígenas, via seleção diferenciada.

8. Há o registro de diversos processos movidos pela Associação dos Povos Indígenas do Tocantins (APITO) e Associação Indígena Gaviāo Kyikatêjê Amtáti junto à reitoria da instituição fazendo tal reivindicação.

9. A respeito do termo nivelamento, é importante frisar que não há como passar despercebida a carga negativa em torno dessa perspectiva que impóe a necessidade de os indígenas nivelarem-se aos padrôes que historicamente cobram desses sujeitos, isto é, uma adequação aos padrões ocidentais. Fica incoerente qualquer ação afirmativa voltada aos indígenas que adote termos que denotam que esses sujeitos estão abaixo de um nível aceitável em todos os âmbitos da sociedade, bem como no caso específico deste trabalho, que é a universidade.

\section{Referências}

ALVES, G.; PASCUETO, C. 200 anos de Ensino Superior. Revista de História, 2008. Disponível em: <http://www.revistadehistoria.com.br/secao/reportagem/200-anos-deensino-superior $>$. Acesso em: 20 set. 2016.

ARNAUD, E. (maio de 1964). Notícias sobre os índios Gavióes do Oeste do Rio Tocantins. Boletim do Museu Paraense Emílio Goeldi, Antropologia, n. 20, 1964.

BRASIL. Lei no 10.639, de 9 de janeiro de 2003. Altera a Lei no 9.394, de 20 de dezembro de 1996, que estabelece as diretrizes e bases da educação nacional, para incluir no currículo oficial da Rede de Ensino a obrigatoriedade da temática 'História e Cultura Afro-Brasileira', e dá outras providências. Diário Oficial da Uniáo, Brasília, 10 jan. 2003. Disponível em: <http://www.planalto.gov.br/ccivil 03/leis/2003/L10.639.htm>. Acesso em: $1^{\circ}$ jun. 2016.

BRASIL. Lei no 12.711, de 29 de agosto de 2012. Dispóe sobre o ingresso nas universidades federais e nas instituiçóes federais de ensino técnico de nível médio e dá outras providências. Diário Oficial da Uniáo, Brasília, 30 ago. 2012. Disponível em: <http://www.planalto. gov.br/ccivil 03/ ato2011-2014/2012/lei/l12711.htm>. Acesso em: 01 jun. 2016.

DELEUZE, G. O que é um dispositivo? In: DELEUZE, G. O mistério de Ariana. Lisboa: Vega/Passagens, 1996. p. 83-96. 
FERRAZ, I. De "Gavióes” a “Comunidade Parkatêjề”: uma reflexáo sobre processos de reorganizaçáo social. Tese (Doutorado) - Universidade Federal do Rio de Janeiro, Rio de Janeiro, 1998.

FOUCAULT, M. A arqueologia do saber. 8. ed. Rio de Janeiro: Forense Universitária, 2014.

FOUCAULT, M. A ordem do discurso. Aula Inaugural no Collège de France. Pronunciada em 2 de Dezembro de 1970. 21. ed. São Paulo: Loyola, 2011.

FOUCAULT, M. Em defesa da sociedade: curso no Collége de France (1975-1976). São Paulo: WMF Martins Fontes, 2010.

FOUCAULT, M. História da sexualidade 1: a vontade de saber. Rio de Janeiro: Ediçóes Graal, 1988.

FOUCAULT, M. Segurança, Território, População. Tradução de Eduardo Brandão. São Paulo: Martins Fontes, 2008.

FOUCAULT, M. Sobre a História da Sexualidade. In: MACHADO, R. (org.). Microfísica do poder. 17. ed. Rio de Janeiro: Graal, 1999. p. 243-276.

GREGOLIN, M. do R. O dispositivo escolar republicano na paisagem das cidades brasileiras: enunciados, visibilidades, subjetividades. Revista Moara, Belém, n. 43, p. 6-25, jan.-jun. 2015. Disponível em: <http://dx.doi.org/10.18542/moara.v1i43.2633>. Acesso em: 22 jun. 2017.

NEVES, I. A invençáo do índio e as narrativas orais Tupi. 158f. Tese (Doutorado em Linguística) - Instituto de Estudos da Linguagem, Universidade Estadual de Campinas, Campinas, 2009.

\section{SOBRE AS AUTORAS}

Flávia Marinho LisbôA é licenciada em Letras pela Universidade Federal do Pará (UFPA) e doutora em Estudos Linguísticos pelo Programa de Pós-Graduação em Letras (UFPA). Desenvolve pesquisa na área de análise do discurso, no entendimento das relaçóes étnico-raciais e de gênero.

IvÂNia dos Santos Neves é licenciada em Letras (UFPA) e doutora em Linguística, na área de análise do discurso, pela Universidade Estadual de Campinas. Desenvolve pesquisa nas áreas de linguística, comunicação e antropologia.

Recebido em 29 de janeiro de 2019.

Aceito em 12 de setembro de 2019. 